\title{
Failure to Sense
}

National Cancer Institute

\section{Source}

National Cancer Institute. Failure to Sense. NCI Thesaurus. Code C63160.

Problem associated with the failure of the device designed to respond to a physical stimulus (as temperature, illumination, motion) to transmit a resulting signal for interpretation or measurement. 